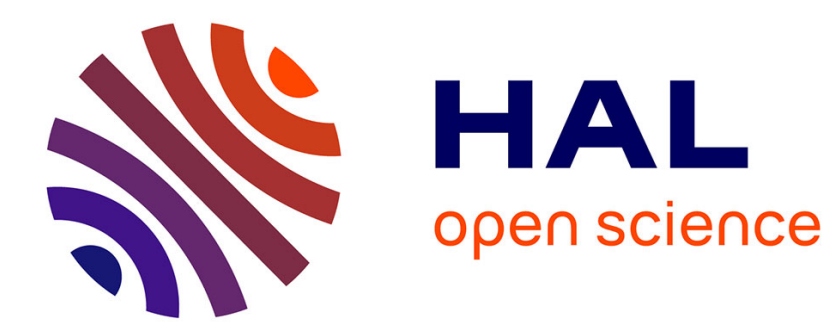

\title{
Operating experience of the upgraded university of Rochester MP tandem \\ T.S. Lund
}

\section{To cite this version:}

T.S. Lund. Operating experience of the upgraded university of Rochester MP tandem. Revue de Physique Appliquée, 1977, 12 (10), pp.1341-1344. 10.1051/rphysap:0197700120100134100 . jpa00244321

\section{HAL Id: jpa-00244321 https://hal.science/jpa-00244321}

Submitted on 1 Jan 1977

HAL is a multi-disciplinary open access archive for the deposit and dissemination of scientific research documents, whether they are published or not. The documents may come from teaching and research institutions in France or abroad, or from public or private research centers.
L'archive ouverte pluridisciplinaire HAL, est destinée au dépôt et à la diffusion de documents scientifiques de niveau recherche, publiés ou non, émanant des établissements d'enseignement et de recherche français ou étrangers, des laboratoires publics ou privés. 


\title{
OPERATING EXPERIENCE OF THE UPGRADED UNIVERSITY OF ROCHESTER MP TANDEM
}

\author{
T. S. LUND \\ Nuclear Structure Research Laboratory, \\ University of Rochester, Rochester, NY 14627, U.S.A.
}

\begin{abstract}
Résumé. - L'augmentation des performances de l'accélérateur Van de Graaff MP de l'Université de Rochester a été entreprise en y introduisant plusieurs dispositifs nouveaux et uniques. Nous décrivons notre expérience en matière de fonctionnement en considérant plus particulièrement les performances du pompage cryogénique au terminal, les tubes accélérateurs à électrodes en titane et à champ incliné spiralé et les performances en transmission et en haute tension pour une variété de faisceaux d'ions lourds intenses.

Les détails de conception du tube accélérateur sont décrits et les performances des tubes présentées avec le point de vue de la tenue en tension et du conditionnement, ainsi que du fonctionnement avec faisceau. Un travail régulier à $12 \mathrm{MV}$ a été obtenu.

La transmission de l'accélérateur a été mesurée pour une variété d'ions allant jusqu'à ${ }^{197} \mathrm{Au}$. Plusieurs états de charge de chaque faisceau ont été analysés en énergie et les résultats obtenus comparés avec les rendements en stripping. La transmission par ${ }^{197} \mathrm{Au}$ dans la gamme de 8-10 MV est de 30-50\%.

Abstract. - The upgrading program for the MP Van de Graaff accelerator at the University of Rochester has been developed with several novel and unique features.

We describe the operating experience of the accelerator with particular emphasis on the performance of the cryogenic terminal pumping, the titanium electrode spiral inclined field acceleration tubes, and the overall accelerator transmission and voltage performance with a variety of high current heavy ion beams.

The design features of the acceleration tubes are described, and the performance of the tubes is presented with regard to static voltage-holding ability and conditioning procedures, as well as operation with beam. Dependable operation exceeding 12MV on terminal has been achieved.

The transmission of the accelerator has been measured for a variety of ion beams up to ${ }^{197} \mathrm{Au}$. Several charge states of each beam were momentum-analyzed, and the results are compared with predicted stripper yields. The transmission performance with ${ }^{197} \mathrm{Au}$ in the range of $8-10 \mathrm{MV}$ terminal voltage was $30-50 \%$.
\end{abstract}

1. Introduction. - At the University of Rochester's Nuclear Structure Research Laboratory, we have been studying the problems and limitations of operating the MP tandem Van de Graaff beyond the original specifications to upgraded voltage levels above $12 \mathrm{MV}$. The efforts to upgrade the performance of this machine have been focussed on several of the fundamental limitations of the original machine. The overall background and initial results of this program have been previously reported $[1,2]$. The present paper describes the operating experience of the accelerator with particular emphasis of the performance of the cryogenic terminal pumping, the titanium electrode spirally inclined field acceleration tubes, and the overall accelerator transmission and voltage performance with a wide variety of high current heavy ion beams.

2. Cryogenic terminal pumping. - A sketch of the cryogenic terminal pumping which has been in operation for over four years is given in figure 1 . Both of the cryogenic units are always in operation when the accelerator is running and the overall reliability of this system has been excellent. After about 19000 hours on each unit, the cold head refrigerators were disassembled for a complete overhaul. One unit showed substantial wear on a bronze cam roller and this unit had essentially reached the end of its useful life. The second unit showed essentially no wear on the critical parts and this unit could probably have operated substantially longer. The bronze cam roller was replaced by a ball bearing which should provide essentially unlimited life, with the major limiting factor as the displacer seals themselves. All in all, 19000 hours without maintenance is most satisfactory. An incidental advantage of these cryogenic pumps is that they can be removed from the vacuum housing for repairs while maintaining the vacuum in the acceleration tubes. This is in contrast to ion pumps or other types of pumps which would have to be isolated with a valve in order to maintain the vacuum in the acceleration tubes. 

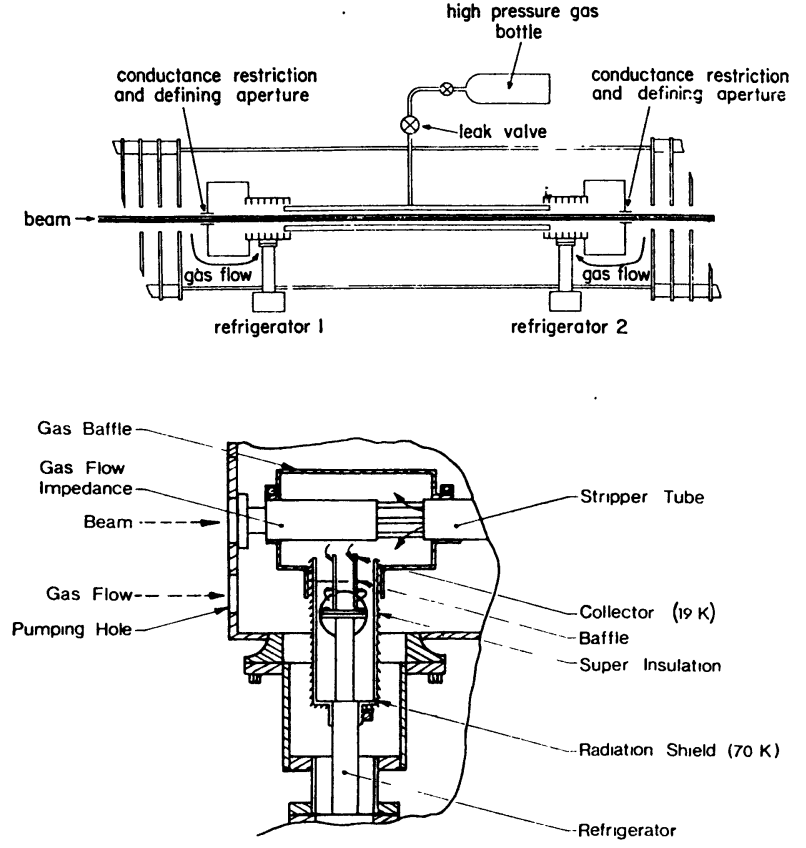

FIG. 1. - Arrangement of cryogenic terminal pumping.

During normal operation with the gas stripper on, all of the gas is effectively pumped by the differential pumping arrangement of the cold surfaces, and the vacuums recorded at the base end of the machine remain at about $5 \times 10^{-8}$ torr. With a normal amount of stripper gas flow, the pumps will easily operate more than four weeks without having to outgas the condensed gas.

3. Acceleration tubes. - Following the initial tests of a single section of the new design of acceleration tube [1], a complete set of eight tubes was installed in the machine. These tubes had aluminium electrodes glued to glass insulators with a nominal outside diameter of $83 / 4$ inches. The voltage performance of the accelerator was substantially improved over the performance with the original 14 inch diameter tubes supplied with the machine from HVEC. Routine operation above $10 \mathrm{MV}$ on terminal was possible for several months. The maximum voltage utilized for experimental work during this period was $11.8 \mathrm{MV}$.

After about 3000 hours, the accelerator performance began to be limited by accelerator tube instability. The principal damage to the tubes consisted of large splotchy patches on the interior of the glass insulators apparently as a result of metal being sputtered from the electrodes. No tracking of the insulator surfaces has been observed. The splotches tend to follow the spiral of the electrostatic suppression suggesting that the sputtering was caused by electrons and suppressed ions.

At the time, it was recognized that the glass insulators were inadequately shielded in the initial design and that more suitable electrode materials were available. A decision was made to rebuild the aluminium electrode tubes with titanium electrodes. The peripheral pumping cutouts were reduced by about $6 \mathrm{~mm}$ on the outside diameter near the glass insulators. The profile of the glass insulator in the vacuum was changed to a re-entrant design to reduce the possibility of sputtered material building up on the surface, and also to reduce the possibility of tracking the glass.

The installation of the titanium electrode tubes was completed in may 1975, and since that time the accelerator has operated reliably at voltages up to $12 \mathrm{MV}$. The experience with the titanium electrode tubes has been exceptionally good. Tube number 4 has operated over 19000 hours, tubes 2 and 7 have been in operation about 15000 hours. Tubes 3, 5, 6, 8 have been running 8000 hours, and tube 1 has over 5000 hours on it. The replacement of these tubes was spread over two budget years by replacing the tubes with the poorest performance first. During the entire life of these acceleration tubes, we have not yet observed a single track mark or broken glass across the insulator surface.

4. Heavy ion transmission. - Measurements have been made at Rochester on the transmission efficiency of the MP tandem using $180 \mathrm{keV}$ injection and beams of ${ }^{32} \mathrm{~S},{ }^{58} \mathrm{Ni},{ }^{197} \mathrm{Au}$ from a refocussed Middleton sputter source and $16 \mathrm{O}$ from an off axis duoplasmatron. These measurements were made by analyzing several charge states of each beam using the $70 \%$ port on the standard analyzing magnet [3]. This port has a radius of curvature of $65^{\prime \prime}$ and allows beams up to $M E / Q^{2}=300 \mathrm{amu}-\mathrm{MeV}$ to be analyzed. The test arrangement for these measurements is shows in figure 2. The standard MP beam transport system was

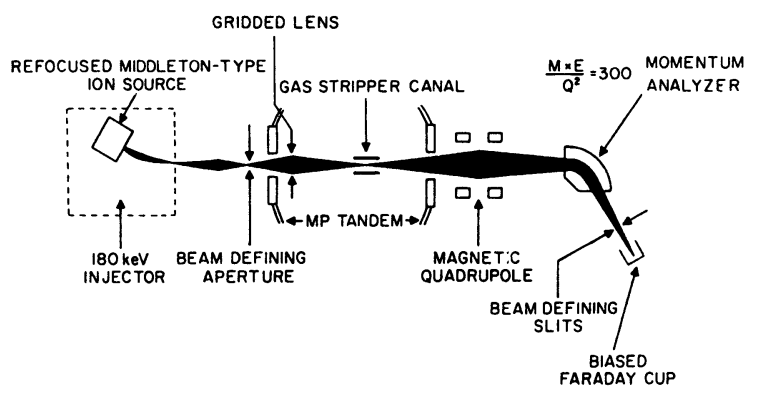

FIG. 2. - Heavy ion transmission test arrangement.

used with the $70^{\circ}$ magnet port described above. The standard object slits were opened wide and the HE magnetic quadrupole focussed the beam through the magnet into the faraday cup. This allowed the HE quadrupole to focus the beams with a longer image distance so that the measurements were not limited by the strength of this lens. The beam defining aperture at the entrance to the accelerator is $4.75 \mathrm{~mm}$ diameter.

Data was taken for terminal voltages between 8 and 10.5 MV. The upper limit to the voltage was set by the fact that the accelerator had been opened only a few hours previously and had not been conditionned. The 
analyzed current was normalized to an equivalent particle current, corrected for known losses due to the gridded entrance lens, and then compared to the predicted charge state fractions given by Betz [4]. A summary of the data is given in figure 3 . Within the

\begin{tabular}{|c|c|c|c|c|c|c|c|}
\hline $\begin{array}{l}\text { BEAM } \\
\text { TYPE }\end{array}$ & $\begin{array}{c}\text { CHARGE } \\
\text { STATE } \\
\theta^{+}\end{array}$ & $\begin{array}{l}\text { I.NJECTED } \\
\text { CURREHT } \\
\text { I }_{L E}(\mu A)\end{array}$ & $\begin{array}{l}\text { ANALYZED } \\
\text { CURRENT } \\
\mathrm{I}_{\theta}+(\mu A)\end{array}$ & $\begin{array}{l}\text { PARTICLE } \\
\text { RATIO }\end{array}$ & $\begin{array}{l}\text { PREDICTED } \\
\text { RATIO }\end{array}$ & $\begin{array}{l}\text { PREDICTED } \\
\text { RATIO AFTER } \\
\text { ALLOWAiNCE } \\
\text { FOR GRID }\end{array}$ & $\begin{array}{l}\text { TRANSMISSION } \\
\text { EFFICIENCY }\end{array}$ \\
\hline 160 & +4 & .500 & .740 & .370 & .461 & .415 & .892 \\
\hline & $\begin{array}{r}4 \\
+5\end{array}$ & .500 & .820 & .328 & .377 & .339 & .968 \\
\hline${ }^{32} \mathrm{~S}$ & +4 & 8.0 & 4.6 & .1438 & 2011 & .1810 & .794 \\
\hline & +5 & 6.2 & 6.2 & .2000 & .3637 & .3273 & .611 \\
\hline$"$ & +6 & 6.2 & 4.0 & .1075 & .2790 & .2511 & .417 \\
\hline$"$ & +7 & 0.1 & 1.1 & .0258 & .0908 & .0817 & .316 \\
\hline$"$ & +8 & 6.0 & .32 & .0067 & .0125 & .0113 & .593 \\
\hline " & +9 & 7.8 & .085 & .0012 & .0007 & .0006 & - \\
\hline${ }^{8} 8 \mathrm{HI}_{\mathrm{I}}$ & +4 & .600 & .300 & .125 & .2269 & .2042 & .622 \\
\hline "I & +5 & .700 & .460 & .131 & .2788 & .2509 & .522 \\
\hline " & +6 & .700 & .360 & .0857 & 2099. & . 1839 & .454 \\
\hline " & +7 & .650 & .220 & .0483 & .0968 & .0871 & .555 \\
\hline " & +8 & .650 & .130 & .0230 & .0274 & .0247 & .931 \\
\hline${ }^{197} \mathrm{Au}$ & +6 & 1.80 & .300 & .0277 & .1346 & .1214 & .228 \\
\hline wo & +7 & 2.30 & .380 & .0236 & .0840 & .0756 & .312 \\
\hline " & +8 & 2.20 & .175 & .0099 & .0424 & .0382 & .259 \\
\hline$"$ & +9 & 2.17 & .070 & .00358 & .0173 & .0156 & .229 \\
\hline " & +10 & 2.05 & .020 & .00097 & .0057 & .0051 & .190 \\
\hline$"$ & +11 & 1.90 & .005 & .00024 & .0015 & .0013 & .185 \\
\hline \multicolumn{8}{|c|}{ ADDITIONAL DATA WITH LE DËFINING APERTURE REMOVED } \\
\hline & +7 & 4.00 & .600 & .0214 & .0846 & .0756 & .283 \\
\hline
\end{tabular}

FIG. 3. - Heavy ion transmission data.

error of the measurements there was no indication that the theoretical charge state distributions had been distorted by stripping in the high energy tubes. Such stripping would tend to remove the low charge state components. Also, there was no indication of losses of high charge state components which would indicate small angle scattering effects. The data which was taken at a fixed stripper gas pressure is consistent with the higher charge states being in equilibrium. Figure 4

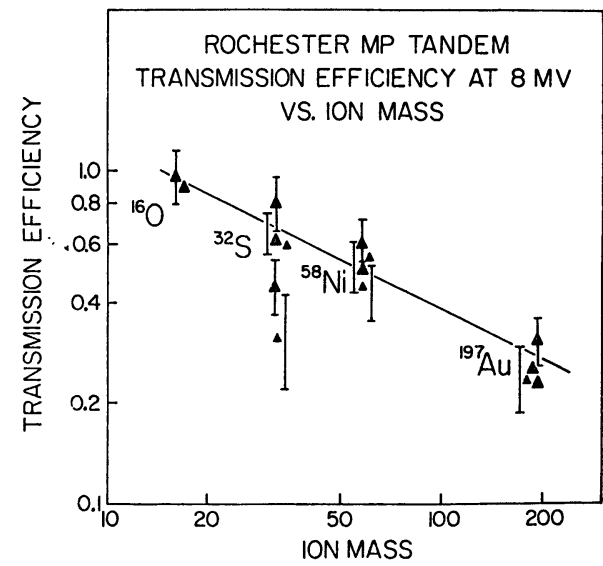

FIG. 4. - Rochester MP Tandem transmission efficiency at $8 \mathrm{MV}$ $v s$. ion mass.

shows a graph of all of the data. It can be seen that the transmission varies from nearly $100 \%$ for $16 \mathrm{O}$ to about $30 \%$ for ${ }^{197} \mathrm{Au}$. The line that has been drawn through the data is consistent with vacuum losses of negative ions in the low energy tubes being the dominant factor in the overall transmission. This result is consistent with measurements at the Heidelberg MP with a faraday cup in the high voltage terminal (1).

( $\left.{ }^{1}\right)$ R. Repnow, private communication.
The important conclusion from this result is that a rather modest decrease in the vacuum pressure is all that is needed to improve the transmission so that it is essentially constant over the periodic table. The installation of a single pumping system in a dead section in the low energy tube would provide the desired improvement in the vacuum.

Measurements were also made using high intensity beams of ${ }^{12} \mathrm{C}$ and ${ }^{32} \mathrm{~S}$ to investigate loading effects. The tandem output current versus input current is plotted in figure 5. This data is a straight line plot

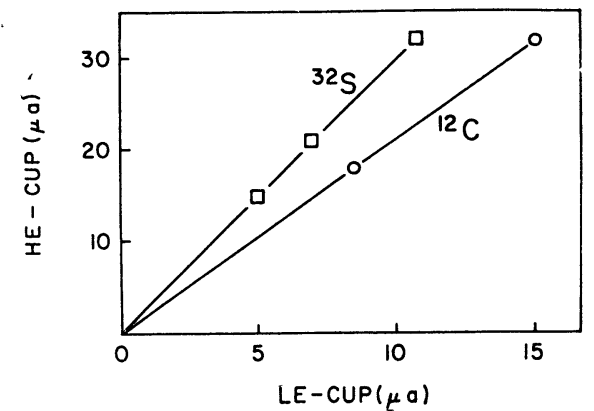

Fig. 5. - Tandem output current vs. input beam.

suggesting that the transmission is consistent with beam intensities up to $15 \mu \mathrm{A}$. Also, the ${ }^{197} \mathrm{Au}$ measurements were made with $2 \mu \mathrm{A}$ and $5 \mu \mathrm{A}$ injected beams, and once again the machine showed no indications of loading phenomena.

5. Overall performance. - Most of the time since the titanium tubes have been installed, the accelerator has been operated above $10 \mathrm{MV}$, and a wide variety of heavy ions have been accelerated. Figure 6 is a sum-

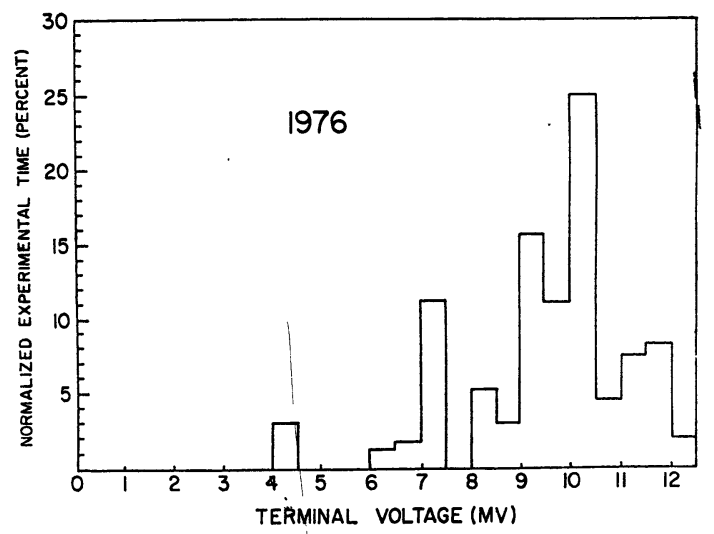

FIG. 6. - Distribution of operating time vs. terminal voltage.

mary of the operating time versus terminal voltage and figure 7 is a summary of the amount of time that various ion beams have been accelerated.

Two other mechanical systems have been installed on the accelerator which have helped improve the overall operation and conditioning. Two spring-loaded cable reels were installed in the high voltage terminal with an insulating monofilament line connec- 


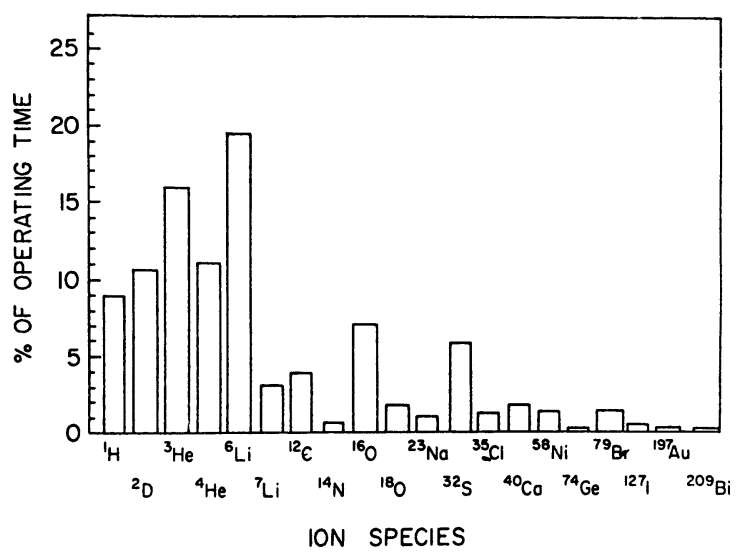

FIG. 7. - Distribution of operating time vs ion species.

ted to a control motor at either end of the machine. These shorting cables allow any dead section of the machine to be electrically connected to the terminal. By using various positions of these shorting cables, together with radial shorting rods through the tank wall, any single acceleration tube section may be conditioned to high gradients without any high gradient on the rest of the machine. The major advantage of this system is the ease with which the machine can be conditioned to high voltage following a tank opening. An an example, following a recent tank opening when the acceleration tubes were let up to atmosphere, each tube section was separately conditioned to about 3.5 MV, and then the entire machine was brought up to voltage. With less than 20 hours of total conditioning, the machine had reached 12.2 MV without any tank or column sparks. Without the use of these shorting cables, this amount of conditioning would have taken several days and there would have been perhaps a dozen or more sparks.
Since there is a finite probability of causing some kind of damage inside of the tank with every spark, anything that can be done to eliminate the sparking, such as this section-by-section conditioning technique, will certainly result in less downtime for intank repairs, and consequently the machine will operate with greater long-term reliability.

Also, an isolation valve has been designed for changing carbon stripping foils while maintaining the acceleration tubes under vacuum. A sketch of this valve is in figure 8 , and it has been installed on the

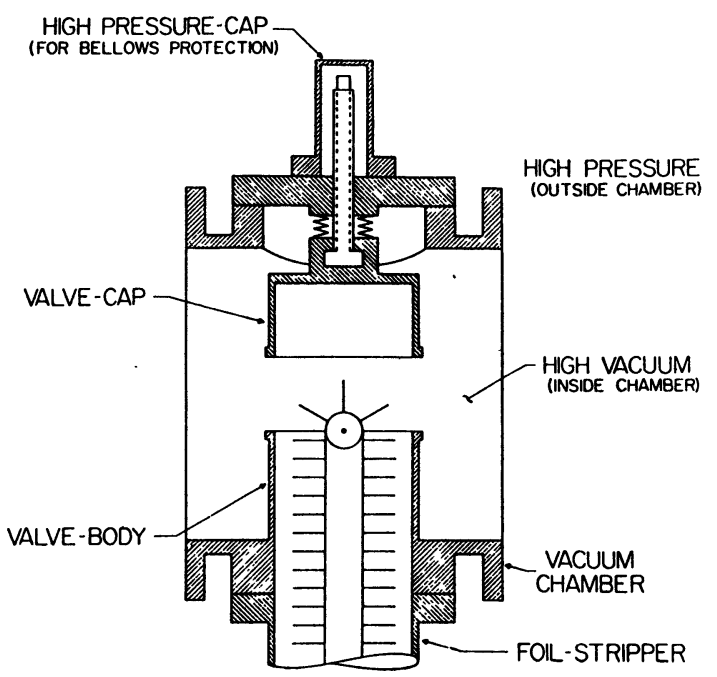

Fig. 8. - Isolation-valve as used in Van de Graaf accelerator.

terminal foil stripper. A second version is under construction for the second foil stripper in the 5-6 dead section. The principal advantages of this design are the high vacuum conductance and the ease of installation in the same vacuum tee as the foil stripper itself.

References

[1] PURSER K. H., International Conference of the Technology of Electrostatic Accelerators, Daresbury, DNPL/NSF/R5, 1973.

[2] Purser K. H., Gove H. E., Lund T. S. and Hyder McK. Nucl. Instrum. Methods. 122 (1974) 159.
[3] Lund T. S., Clover M. R., Gove H. E. and Purser K. H., 1977 Particle Accelerator Conference, to be published IEEE Trans. Nucl. Sci.

[4] Betz H. D., Rev. Mod. Phys. 44 (1972) 460. 